Original Article

\title{
Assessment on determinants of contraceptive morbidity in Northeast India
}

\author{
Pralip Kumar Narzary ${ }^{\mathrm{a}, *}$, Moatula Ao ${ }^{\mathrm{b}}$ \\ a International Institute for Population Sciences, Mumbai-88, India \\ ${ }^{\mathrm{b}}$ P G Dept. of Population Studies, Fakir Mohan University, Balasore, Odisha, India
}

\section{A R T I C L E I N F O}

\section{Article history:}

Received 12 June 2017

Accepted 20 December 2017

Available online 23 December 2017

\section{Keywords:}

Contraceptive morbidity

Northeast India

Family Planning

Tribal

Contraceptive use

\begin{abstract}
A B S T R A C T
Introduction: With the increase in widening role of women, need for family planning and contraceptive use is ever increasing. Healthy reproductive and sexual health for many women is still a dream in Northeast India. Bulk of women are unaware about morbidity associated with the contraceptive use as the service providers usually do not provide information on side-effects to the user thus women suffer silently, which ultimately may lead to severe health consequences.

Objectives: Present study aims to understand the pattern of contraceptive use and morbidity associated with it.

Methods: Present study uses District Level Household and Facility Survey 2012-2013 (DLHS-4) data of seven North-eastern states of India. Only the currently married women (CMW) who are usual resident and not pregnant are retained. Hence a sample of 30,670 CMW are kept for assessing contraceptive use, subsequently 7,825 CMW are filtered for understanding contraceptive morbidity. Statistical technique like Cramer's V and Phi test, and logistic regression are used for the analysis.

Results: Result shows that the percentage of using modern contraceptive method was highest in Sikkim and lowest in Meghalaya. Key findings of the present study are that women with higher parity, having information about side effects and belonging to non-tribal community are more likely to report having contraceptive morbidity, whereas it is opposite for the users of modern spacing methods Conclusion: Higher parity women in particular should be provided information about proper use and side-effects of modern contraceptives, so that they can make an informed choice of contraception and lead a healthy life.
\end{abstract}

(C) 2017 Published by Elsevier, a division of RELX India, Pvt. Ltd on behalf of INDIACLEN.

\section{Introduction}

India, which is the second most populated country after China, adopted family planning programme about seven decades back to control fertility, unwanted pregnancies and reproductive health problems. Yet there is great variation across the states and socioeconomic strata in terms of percentage of contraceptive use, unmet need, method mix etc. Large scale surveys show that female sterilization is the very dominant method compared with all other contraceptive methods in India. But it is not so in some parts of Northeast India. Further, women are less aware about the side effects of using modern contraceptive or contraceptive morbidities. Contraceptive morbidities are defined in two broad types; local effects of contraception include irritation or allergics reaction,

\footnotetext{
* Corresponding author

E-mail addresses: pralipkn@iips.net (P.K. Narzary), jamirmoatula2@gmail.com (M. Ao).
}

IUD associated bleeding or infections at wound side (implants or tubal sterilization) and systematic effects includes impact on the cardiovascular and hormonal system and carcinogenicity. ${ }^{1}$ Study suggests that women who know of a range of method options and who are well informed about the side effects and problems associated with various methods are in a better position to make an informed choice about contraception. ${ }^{2}$

According to the recent National Family Health Survey-4 (201516) fact sheet use of any modern contraceptive method is $47.8 \%$ in India, ${ }^{3}$ which has slightly declined from $48.5 \%$ since NFHS-3 (2005$06){ }^{2}$ Contraceptive method plays a very crucial role in regulating reproduction process. With the increase in level of education, exposure to mass media, opportunities to work outside home, women's widening role at home and outside, etc., the need for family planning and contraceptive use is ever increasing. But it is known fact that every method has some costs associated with it. One of them is cost of availing the method, another is experiencing side effects or morbidity. Though, many a times it may be due to the wrong (self) selection of the method. However, women around 
the globe report experiencing some contraceptive morbidity owing to the use of modern contraceptive method. A study based on 60 demographic health survey exhibits that method-related dissatisfaction is the most common reason for discontinuation for all methods except periodic abstinence and withdrawal, for which failure is more common ${ }^{4}$ and couples opt for traditional method due to fear of side effects, healthier and easier to use. ${ }^{5,6}$ Other study shows that among the women who are in need of contraception, the percentage of discontinuations due to side effects ranged from 2 percent in Armenia to 37 percent in Egypt. ${ }^{7}$ Study conducted in Kinshasa suggests that fear of side effects as the leading reason for non-use of modern contraception. ${ }^{8}$ Such fear might have come from own past experience, word of others' mouth, or observation, etc., and most of the time such perception turns out to be true. ${ }^{9}$ Other study suggests that the intensity of side effects associated with a sterilization operation or IUD insertion may compound the prevalence of reproductive tract infections. ${ }^{10}$ Other study also found that ${ }^{11}$ side effects caused by modern contraceptive is the main reason for forgoing family planning and discontinuation. Thus it is clear that side effect or contraceptive morbidity may cause non-use as well as discontinuation.

Usually women are trapped between regulating the reproduction and facing the contraceptive morbidity. As such, healthy reproductive and sexual life is still a dream for many women, and particularly for women in northeast India. Study reveals that the demand for family planning among the states and union territories in India is highly diverse, and greatest attention is needed in Uttar Pradesh, Manipur, and Meghalaya to meet United Nation's targets. $^{12}$ As such policies adopted at the national level may not be appropriate for some regions. Because, research relating to access to family planning focused on at the national level might not detect the local diversity. ${ }^{12}$ Similarly, studies relating to contraceptive morbidity at national level may not be able to capture the regional diversities. Northeast India being the land of hundreds of tribal communities, is quite different from rest of the country. Further, method mix in northeast India does not follow overall Indian pattern. Further, studies relating to contraceptive use and morbidity on northeast India is hard to find. Hence, knowing the prevalence and determinants of contraceptive morbidity in northeast India is essential, so that the appropriate strategies can be adopted.

\section{Methods}

For achieving the objectives of the study, District Level Household and Facility Survey-4 (DLHS-4) data which was collected during the period 2012-2013 was used. DLHS-4 is a multi-stage stratified designed adopted for selection of representative sample of each district. The rural and urban areas of a district were considered as natural strata. Both in urban and rural areas two stage-sampling was made. In urban area the primary sampling unit is the National Sample Survey Organization urban frame survey blocks and second stage sampling unit is the household. In rural area, census village is considered as the primary sampling unit and household as the second sampling unit. ${ }^{13}$ (for details of the DLHS, visit - www.iipsindia.org). Although information was collected from non-empowered action groups (EAG) states, the present study uses information of only seven north-eastern states of India. It collected information from 15-49 years old ever married and never married women. But in this study, data of currently married women (CMW), usual resident and not pregnant are used. Hence, total 30,670 CMW are retained for the analyses of assessing contraceptive use. Later, to assess the contraceptive morbidity, only a sample of 7825 CMW who are current user of modern contraceptive methods are retained ( 7 cases whose husband has undergone male sterilization are also removed from the analysis).
Further, due to the missing cases in variable relating to "whether a woman is informed about side effect ( 214 missing cases) and parity (3 missing cases) sample got reduced to $7608 \mathrm{CMW}$ in running multi-variate statistics. Bi-variate analysis is used to examine the relationship between variables and its strength assessed by Cramer's-V or phi test. Binary logistic regression is applied to examine the determinants of the outcome variable - contraceptive morbidity. Entire analyses are carried out in SPSS version-20.

\subsection{Dependent variable}

Relating to side effects due to contraceptive use, the DLHS-4 asked 'Have you/your husband had any health problems after you/ your husband started to use this (NAME) method? If the answer to this question is "YES", another question was "What health problem (s) did you/your husband has?' Within this question information relating to following 18 side effects were collected - 1) Weakness/ inability to work, 2) Body ache/backache, 3) Abdominal pain, 4) Weight gain, 5) Dizziness, 6) Nausea/vomiting, 7) Fever, 8) Breast tendering, 9) Irregular periods, 10) Excessive bleeding, 11) Spotting, 12) Amenorrhoea, 13) Cramps, 14) Scrotum swelling, 15) Decreased libido, 16) Rashes/allergy, 17) Infection, and 18) Other. 'Other' category may include anything besides the listed side effects. These are multiple response questions, so a woman may report having 'all', 'some' or 'none' of them. In the present study, if a woman is facing anyone of the 18 mentioned side effects, she is considered as having contraceptive morbidity (coded as 1 ), otherwise not (coded as 0$)$.

\section{Results}

\subsection{Pattern of contraceptive use}

As a background of contraceptive morbidity, it is pertinent to first assess the level of contraceptive use and distribution of sample in the region. It is evident that overall slightly over onethird of CMW in Northeast India are current user of contraceptive method (Table 1). The contraceptive use is lowest in the state of Meghalaya (13.6\%), whereas it is highest in the state of Sikkim (60.4\%). One of the interesting findings is that the percentage of traditional methods users is significantly high in the state of Tripura. Further, the proportion of traditional method users to total contraceptive users is very high in the state of Manipur (49\%), and considerably high in the states of Tripura (43.4\%), Meghalaya (39\%) and Nagaland (34.2\%). But in Mizoram use of traditional method is negligible (3\%). One of the studies conducted in Meghalaya report that none (of the women respondents) had seen an IUD before, and the men were particularly concerned about the effects of this form of contraception on a woman's body. ${ }^{14}$ For the lack of knowledge full range of methods and the fear of morbidity, women may be resorting to traditional methods in northeast India.

\subsection{Differentials of contraceptive morbidity}

Percentage of CMW currently using contraception by type of contraceptive morbidity is presented in Table 2. Result shows that among the sterilized women, body ache/backache $(4.5 \%)$ is the most reported morbidity followed by abdominal pain (3.6\%) and irregular periods (2.3\%). Among the IUD users 2.1 percent reported abdominal pain, whereas 1.9 percent reported to have suffered from body ache/backache. For pills/injectable users, weakness/ inability to work is the morbidity reported by maximum number of women. Interestingly, among the condom users, body ache/ backache is the leading contraceptive morbidity. However, it is difficult to draw inference due to the very small sample size. It is worth noting here that hardly anyone reported some of the 
Table 1

Pattern of contraceptive use in northeast India.

\begin{tabular}{|c|c|c|c|c|c|}
\hline State & $\begin{array}{l}\text { Distribution } \\
\text { of women } \\
\text { by state }\end{array}$ & $\begin{array}{l}\text { Percentage of } \\
\text { women using } \\
\text { modern method }\end{array}$ & $\begin{array}{l}\text { Percentage of } \\
\text { women using } \\
\text { traditional } \\
\text { methods }\end{array}$ & $\begin{array}{l}\text { Percentage } \\
\text { of non-users }\end{array}$ & $\begin{array}{l}\text { Proportion of } \\
\text { traditional } \\
\text { method users } \\
\text { to total users }\end{array}$ \\
\hline Sikkim & 2,248 & 46.4 & 14.0 & 39.7 & 23.2 \\
\hline Arunachal & 8,715 & 31.0 & 6.8 & 62.2 & 18.0 \\
\hline Nagaland & 4,543 & 21.0 & 10.9 & 68.1 & 34.2 \\
\hline Manipur & 5,602 & 10.7 & 10.3 & 79.0 & 49.0 \\
\hline Mizoram & 3,126 & 41.7 & 1.3 & 56.9 & 3.0 \\
\hline Tripura & 2,900 & 32.1 & 24.6 & 43.2 & 43.4 \\
\hline Meghalaya & 3,536 & 8.3 & 5.3 & 86.4 & 39.0 \\
\hline Total & 30,670 & 25.5 & 9.5 & 64.9 & 27.1 \\
\hline
\end{tabular}

contraceptive morbidities like amenorrhea, decreased libido, breast tendering, spotting and rashes/allergy. Overall the percentage of women reporting anyone of the 18 contraceptive morbidities is maximum among the sterilized women (9\%) followed by IUD $(5.8 \%)$ users and Pill \& injectable (4.8\%), whereas it is minimum among the condom users (2.3\%). In total, 5 percent of CMW who are currently using modern contraceptive methods have reported experiencing any one of the morbidities (Table 2).

The bi-variate statistical result (Table 3 ) shows a pretty weak and statistically insignificant linkage between age of the women and contraceptive morbidity. Education, though is assumed to have significant bearing in contraceptive morbidity, did not show statistically significant relationship. Other study argues that women's education seems to be an important factor facilitating both awareness of reproductive health complications and precautionary measures to take in avoiding complications. ${ }^{10}$ A weak but statistically highly significant association between parity and the contraceptive morbidity is observed. In other words, with the increase in parity, women are more likely to suffer from contraceptive morbidity. With the increase in marital duration, normally the need to use a contraception increases, women are significantly likely to experience more contraceptive morbidity. Theoretically the duration of contraceptive use has the most direct bearing on the contraceptive morbidity. But statistically the relationship looks to be quite feeble and insignificant. Among the women who were informed about the side effects, reporting of contraceptive morbidity is also quite higher and the relationship is statistically highly significant. The reporting of contraceptive morbidity is significantly higher if they were informed by the mother-in-law/mother/relatives/friends/others (result not shown). There is marginal difference in reporting contraceptive morbidity across the women of different religions and the relationship is weak. However, this result is statistically significant. In terms of reporting of the contraceptive morbidity, a significant difference between tribal and non-tribal women is noted. It is much higher among the non-tribal than the tribal women. Very weak and statistically insignificant rural-urban differences in reporting of contraceptive morbidity is observed. Type of house, which is taken as proxy of economic condition of the household, does not show a significant relationship with contraceptive morbidity. One of the most apparent characteristics to have a close linkage with the contraceptive morbidity is the method of contraceptive use. In this context result shows that reporting of contraceptive morbidity is highest among the women who are currently sterilized, followed by users of IUD and Pills. This relationship is also statistically highly significant.

\subsection{Determinants of contraceptive morbidity}

To find out the determinants of contraceptive morbidity, binary logistic regression is run by taking the variables which have shown significant relationship with contraceptive morbidity in bi-variate analysis. It is found (Table 4) that with the increase in parity, women are more likely to report having contraceptive morbidity (Odds Ratio:1.171) and it is statistically quite significant. There is an indication that with the increase in marital duration, women are less likely to report having contraceptive morbidity, but the result is not significant. The women who were informed about side effect

Table 2

Percentage of CMW currently using contraception by type of contraceptive morbidity.

\begin{tabular}{|c|c|c|c|c|c|}
\hline Side effects & $\begin{array}{l}\text { Female } \\
\text { Sterilization }\end{array}$ & IUD & $\begin{array}{l}\text { Pill \& } \\
\text { injectable }\end{array}$ & Condom & Overall \\
\hline 1) Weakness/inability to work & $1.8(4)$ & $1.2(18)$ & $1.5(73)$ & $0.4(6)$ & $1.3(101)$ \\
\hline 2) Body ache/backache & $4.5(10)$ & $1.9(29)$ & $1.4(64)$ & $0.7(10)$ & $1.4(113)$ \\
\hline 3) Abdominal pain & $3.6(8)$ & $2.1(32)$ & $0.6(27)$ & $0.1(1)$ & $0.9(68)$ \\
\hline 4) Weight gain & $0.5(1)$ & $0.4(6)$ & $0.2(9)$ & $0.4(5)$ & $0.3(21)$ \\
\hline 5) Dizziness & $0.9(2)$ & $0.2(3)$ & $0.5(23)$ & $0.0(0)$ & $0.4(28)$ \\
\hline 6) Nausea/vomiting & $0.0(0)$ & $0.0(0)$ & $0.5(23)$ & $0.2(3)$ & $0.3(26)$ \\
\hline 7) Fever & $0.0(0)$ & $0.3(5)$ & $0.2(11)$ & $0.3(4)$ & $0.3(20)$ \\
\hline 8) Breast tendering & $0.0(0)$ & $0.0(0)$ & $0.1(4)$ & $0.0(0)$ & $0.1(4)$ \\
\hline 9) Irregular periods & $2.3(5)$ & $1.2(18)$ & $0.9(44)$ & $0.0(0)$ & $0.9(67)$ \\
\hline 10) Excessive bleeding & $0.5(1)$ & $0.8(12)$ & $0.2(11)$ & $0.0(0)$ & $0.3(24)$ \\
\hline 11) Spotting & $0.5(1)$ & $0.1(1)$ & $0.0(1)$ & $0.1(1)$ & $0.4(4)$ \\
\hline 12) Amenorrhea & $0.0(0)$ & $0.0(0)$ & $0.0(1)$ & $0.0(0)$ & $0.0(1)$ \\
\hline 13) Cramps & $0.5(1)$ & $0.1(1)$ & $0.0(1)$ & $0.0(0)$ & $0.0(3)$ \\
\hline 14) Scrotum swelling & $0.0(0)$ & $0.0(0)$ & $0.0(1)$ & $0.1(1)$ & $0.0(2)$ \\
\hline 15) Decreased libido & $0.0(0)$ & $0.1(1)$ & $0.0(0)$ & $0.0(0)$ & $0.0(1)$ \\
\hline 16) Rashes/allergy & $0.0(0)$ & $0.1(1)$ & $0.0(0)$ & $0.2(3)$ & $0.1(4)$ \\
\hline 17) Infection & $0.5(1)$ & $0.2(3)$ & $0.1(5)$ & $0.0(0)$ & $0.1(9)$ \\
\hline 18) Other problem & $0.9(2)$ & $0.3(5)$ & $0.4(18)$ & $0.1(2)$ & $0.3(27)$ \\
\hline Having anyone of the above & $9.0(20)$ & $5.8(87)$ & $4.8(226)$ & $2.3(32)$ & $4.7(365)$ \\
\hline Total current users & 222 & 1492 & 4717 & 1394 & 7825 \\
\hline
\end{tabular}

Note: figure inside the parenthesis refers to number of women. 
Table 3

Percentage of CMW experiencing contraceptive morbidity by background characteristics.

\begin{tabular}{|c|c|c|c|c|c|}
\hline \multirow[t]{2}{*}{ Independent variables } & \multirow{2}{*}{$\begin{array}{l}\text { Have } \\
\text { morbidity }\end{array}$} & \multirow{2}{*}{$\begin{array}{l}\text { No } \\
\text { morbidity }\end{array}$} & \multicolumn{2}{|c|}{ Cramer's V/Phi } & \multirow[t]{2}{*}{$\mathrm{N}$} \\
\hline & & & Value & $\mathrm{p}$ value & \\
\hline \multicolumn{6}{|l|}{ Age } \\
\hline$<25$ & 4.4 & 95.6 & 0.011 & .922 & 1274 \\
\hline $25-29$ & 4.5 & 95.5 & & & 1997 \\
\hline $30-34$ & 4.7 & 95.3 & & & 1754 \\
\hline $35-39$ & 5.1 & 94.9 & & & 1453 \\
\hline$>39$ & 4.7 & 95.3 & & & 1347 \\
\hline \multicolumn{6}{|l|}{ Women education } \\
\hline No formal schooling/illiterate & 4.5 & 95.5 & 0.026 & .253 & 1924 \\
\hline Primary & 5.2 & 94.8 & & & 1994 \\
\hline Middle & 4.3 & 95.7 & & & 1915 \\
\hline Secondary & 5.4 & 94.6 & & & 1070 \\
\hline Above secondary & 3.7 & 96.3 & & & 922 \\
\hline \multicolumn{6}{|l|}{ Parity } \\
\hline 0 & 1.2 & 98.8 & 0.062 & .000 & 336 \\
\hline 1 & 3.4 & 96.6 & & & 1810 \\
\hline 2 & 4.6 & 95.4 & & & 2350 \\
\hline 3 & 6.4 & 93.6 & & & 1598 \\
\hline 4 & 4.3 & 95.7 & & & 901 \\
\hline $5+$ & 5.9 & 94.1 & & & 830 \\
\hline \multicolumn{6}{|l|}{ Marital duration } \\
\hline$\leq 10$ years & 4.0 & 96.0 & 0.031 & .007 & 3759 \\
\hline $11 \geq$ Years & 5.3 & 94.7 & & & 4066 \\
\hline \multicolumn{6}{|l|}{ Duration of use } \\
\hline Upto 1 year & 4.7 & 95.3 & 0.024 & .065 & 2237 \\
\hline 1-2 Years & 5.8 & 94.2 & & & 3595 \\
\hline Do not remember & 2.8 & 97.2 & & & 1745 \\
\hline \multicolumn{6}{|l|}{ Informed about side effects } \\
\hline No & 3.8 & 96.2 & 0.105 & .000 & 6353 \\
\hline Yes & 9.9 & 90.1 & & & 1258 \\
\hline \multicolumn{6}{|l|}{ Religion } \\
\hline Hindu & 5.4 & 94.6 & 0.030 & .032 & 2445 \\
\hline Christian & 4.0 & 96.0 & & & 3403 \\
\hline Others & 4.9 & 95.1 & & & 1977 \\
\hline \multicolumn{6}{|l|}{ Tribe } \\
\hline ST & 4.1 & 95.9 & 0.044 & .000 & 5505 \\
\hline Others & 6.1 & 93.9 & & & 2320 \\
\hline \multicolumn{6}{|l|}{ Place of residence } \\
\hline Rural & 4.6 & 95.4 & 0.003 & .813 & 5936 \\
\hline Urban & 4.8 & 95.2 & & & 1889 \\
\hline \multicolumn{6}{|l|}{ Type of house } \\
\hline Pucca & 4.1 & 95.9 & 0.018 & .279 & 1425 \\
\hline Semi pucca & 4.5 & 95.5 & & & 2584 \\
\hline Kachcha & 5.0 & 95.0 & & & 3816 \\
\hline \multicolumn{6}{|l|}{ Method of contraceptive use } \\
\hline Female Sterilization & 9.0 & 91.0 & 0.064 & .000 & 222 \\
\hline IUD & 5.8 & 94.2 & & & 1492 \\
\hline Pill \& injectable & 4.8 & 95.2 & & & 4717 \\
\hline Condom & 2.3 & 97.7 & & & 1394 \\
\hline Total & 4.7 & 95.3 & - & - & 7825 \\
\hline
\end{tabular}

Note: cases in some variable may not add up to total due to the missing cases.

of contraceptive method are significantly more likely to report having contraceptive morbidity (OR:2.750) than who were not informed. The religion does not seem to have any significant impact on reporting contraceptive morbidity. Compared to the scheduled tribe women, other women are more likely to report contraceptive morbidity (OR: 1.541). It is notable that the method of current contraceptive use has significant impact on contraceptive morbidity. Compared to women who have adopted sterilization, users of other temporary methods are less likely to report having contraceptive morbidity. Assessment of linkage between the state and the contraceptive morbidity shows that only Manipur shows a significant relationship. Compared to Sikkim, women from Manipur are more likely to report having contraceptive morbidity.

\section{Discussion}

A major concern for family planning programme managers is the discontinuation of contraceptive methods, either voluntarily or 
Table 4

Result of binary logistic regression $(n=7608)$.

\begin{tabular}{|c|c|c|c|c|c|c|}
\hline \multirow{3}{*}{ Independent variables } & \multicolumn{6}{|c|}{ Dependent variables $=$ Status of contraceptive morbidity: Have morbidity $=1$; Don't have morbidity $=0$} \\
\hline & \multirow[t]{2}{*}{ Categories } & \multirow[t]{2}{*}{ B } & \multirow[t]{2}{*}{ Sig. } & \multirow[t]{2}{*}{$\operatorname{Exp}(B)$} & \multicolumn{2}{|c|}{ 95\% CI for $\operatorname{Exp}(\mathrm{B})$} \\
\hline & & & & & Lower & Upper \\
\hline Parity (cont) & & 0.158 & 0.000 & 1.171 & 1.076 & 1.274 \\
\hline Marital duration (cont) & & -0.005 & 0.586 & 0.995 & 0.976 & 1.014 \\
\hline \multirow[t]{2}{*}{ Informed about side effects } & Not informed ${ }^{(r e f)}$ & & & & & \\
\hline & Informed & 1.011 & 0.000 & 2.750 & 2.180 & 3.468 \\
\hline \multirow[t]{3}{*}{ Religion } & Hindu $^{(\mathrm{ref})}$ & & & & & \\
\hline & Christian & -0.237 & 0.166 & 0.789 & 0.564 & 1.103 \\
\hline & Others & -0.005 & 0.976 & 0.995 & 0.728 & 1.361 \\
\hline \multirow[t]{2}{*}{ Ethnicity } & Scheduled Tribe ref) & & & & & \\
\hline & Others & 0.432 & 0.004 & 1.541 & 1.149 & 2.065 \\
\hline \multirow[t]{4}{*}{ Method of current contraceptive use } & Sterilization (ref) & & & & & \\
\hline & IUD & -0.616 & 0.022 & 0.540 & 0.319 & 0.915 \\
\hline & Pills \& Injectables & -0.773 & 0.002 & 0.462 & 0.280 & 0.762 \\
\hline & Condom & -1.305 & 0.000 & 0.271 & 0.149 & 0.493 \\
\hline Constant & & - & 0.000 & 0.058 & & \\
\hline
\end{tabular}

Note: ${ }^{\text {cont. }}=$ Continuous variable; ${ }^{\text {ref }}=$ Reference category .

due to method failure. ${ }^{2}$ Study also suggests that the intensity of side effects associated with a sterilization operation or IUD insertion may compound the prevalence of RTIs. ${ }^{10}$ To address such an important issue, one of the ways is to first understand the determinants of contraceptive morbidity. Hence, if we know the pattern, differentials and determinant of contraceptive morbidity, the appropriate corrective measures can be adopted. This study found that marital duration does not have significant effect on contraceptive morbidity, rather it is the parity. As the parity exerts more pressure on contraceptive use, thereby also expose the women to the morbidity. The women who are aware about the possible side effects of contraceptive use are more likely to report contraceptive morbidity. The other group of women may not be able to associate even the genuine morbidity due to the lack of information, thereby under report it. On the other hand, the women who are informed may associate various health problems, even which may not be outcome of contraceptive use, thereby are more likely to over report ${ }^{15}$ and women may switch from modern contraceptive which are associated with side effects to lesser effective traditional method. The policy implication is that do not simply inform women about side effects, impart them correct information on side effects. Then women may be well prepared to tackle possible morbidities and will not remain aloof from using contraception due to the fear of side effects. In northeast India also non-tribal women are more likely to report contraceptive morbidity. Though tribal women in northeast India are betteroff than the tribal women of mainland, but they may presume those side effects unavoidable part of contraceptive use. Thus, may not report the ailments. Further, as many of the tribal communities still live in remote inaccessible areas, they may be less informed about side effects. Whereas, non-tribal communities are better located in terms of accessibility, and equipped with better information. Present study shows that compared to sterilized women, IUD, Pill and Condom users are less likely to report contraceptive morbidity and it is similar to other study ${ }^{16}$ conducted in India. The reason for higher reporting among sterilized women may be because the procedure of sterilization needed open surgery and the scare always reminded women of the operation they have undergone. In other words, the fear of operation, mostly remain fresh in the mind of women and thereby they associate various morbidities to sterilization. With the recent development of tubectomy, the procedure of open surgery is no more required. Hence, the hospitalization and the necessity to take pre-caution have gone down drastically. However, many women may not be aware about such developments. Further, women should be made aware about all the available methods of contraception and associated morbidity. They should be suggested appropriate method suiting her body and family plan. It should not be method specific family planning program; indeed, the women should be able to choose and use a method suitable to her family planning. Irrespective of the statistical significance, there is a need to make all women aware about contraceptive morbidity and its precautionary measures in all the states of the region.

One of the weaknesses of the present study is that the sample size on contraceptive morbidity is very small, which did not allow deep statistical analysis. Another weakness is that it is the selfreported morbidity, not supported by clinical examination and laboratory tests. Yet, present study could throw some light on one of the pertinent reproductive health problems, using the latest large scale survey data of the whole north eastern region.

\section{Conclusion}

The prevalence of contraceptive morbidity is reasonably low in Northeast India. But there is no denying the fact that side effect or contraceptive morbidity is one of the leading causes of discontinuation of contraceptive use among the women who actually are inneed of contraception and that may be true for women in northeast India. The discontinuation of contraception can lead to increase in unwanted pregnancy, unwanted births, abortion, poor health of women etc. Thus, steps are needed to check the contraceptive morbidity. Informed decision making in contraceptive use is important in healthcare and also on the ground of human rights in accessing contraceptive so that couple can make choices according to their own needs and demand. Cultural factor may also lead to underreporting of the contraceptive morbidity as in a society aetiology of a disease matters in demanding as well as reporting of a disease. As Northeast India is mostly dominated by tribal population, the way of defining a disease may differ and women may not be aware of the contraceptive morbidity. Therefore, more research is needed to formulate proper reproductive health policies to provide safe and accessibility to modern contraceptive beyond effectiveness of contraception.

\section{Conflict of Interest}

The authors declare that there is no conflict of interest. 


\section{References}

1. Fortney JA. Reproductive Morbidity a Conceptual FrameWork. https://www. semanticscholar.org/paper/Reproductive-Morbidity-A-ConceptualFramework-Fortney/5c5c7354b1b6823f867e771a753ca5618466604b.

2. International Institute for Population Sciences (IIPS), Macro International. National Family Health Survey (NFHS-3), 2005-06: India, Volume IMumbai: IIPS; 2007.

3. National Family Health Survey-4 2015-16, India Fact Sheet. http://rchiips.org/ NFHS/factsheet_NFHS-4.shtml.

4. Ali Mohamed M, Cleland John, Shah Iqbal H. Causes and consequences of contraceptive discontinuation: Evidence from 60 demographic and health surveys. World Health Organization Geneva; 2012.

5. Ortayli N, Bulut A, Ozugurlu M, Cokar M. Why withdrawal? Why not withdrawal? Men's perspectives. Reprod Health Matters. 2005;13(25):164-173.

6. Yanikkerem E, Acar H, Elem E. Withdrawal users; perceptions of and experience with contraceptive methods in Manisa, Turkey. Midwifery. 2006;22:274-284.

7. Bradley Sarah EK, Schwandt Hilary M, Khan Shane. Levels, trends, and reasons for contraceptive discontinuation. DHS analytical studies No. 20. Calverton, Maryland, USA: ICF Macro; 2009.

8. Muanda Mbadu, Gahungu Ndongo Parfait, Taub Leah D, Bertrand Jane T. Barriers to modern contraceptive use in Kinshasa, DRC. PLoS One. 2016;11(12): e016756010.1371/journal.pone.0167560.
9. Narzary Pralip Kumar. Perceived constraints among adolescent girls in accessing health care in Assam, India. Int J Pub Health Res. 2012;2(1):55-64.

10. Gulati SC, Chaurasia Alok R, Singh Raghubansh M. Women's reproductive morbidity and treatment-seeking behaviour in India. Asian Popul Stud. 2009;5(1).

11. Chebet JJ, McMahon SA, Greenspan JA, et al. Every method seems to have its problems- perspectives on side effects of hormonal contraceptives in Morogoro Region, Tanzania. BMC Women's Health. 2015;15(97):1-12.

12. New JR, Cahill N, Stover J, Gupta YP, Alkema L. Levels and trends in contraceptive prevalence, unmet need, and demand for family planning for 29 states and union territories in India: a modelling study using the Family Planning Estimation Tool. Lancet Glob Health. 2017;5:e350-58 2017.

13. International Institute for Population Sciences. District level household and facility survey (DLHS-4), 2012-13: India. Manipur: Mumbai: IIPS; 2014.

14. Oosterhoff P, Dkhar B, Albert S. Understanding unmet contraceptive needs among rural Khasi men and women in Meghalaya. Cult Health Sex. 2015;17 (9):1105-111810.1080/13691058.2015.1042918.

15. Sadana R, Snow R. Balancing effectiveness: side effects and work: women's perception and experiences with modern contraceptive technology in Cambodia. Soc Sci Med. 1999;49:343-358.

16. Ram F, Rangaiyan G, Jayachandran V. Contraceptive morbidity: is it an alarming issue in India? IASSI Q. 1997;16(3 \& 4):159-171. 